\title{
Physiopathology of symptoms and signs in multiple sclerosis
}

\author{
Fisiopatologia dos sintomas e sinais na esclerose múltipla
}

Maria José Sá

\begin{abstract}
The physiopathology of symptoms and signs in multiple sclerosis (MS) is a less divulged topic albeit its importance in the patients' management. Objective: It was to summarize the main biophysical and biochemical mechanisms which produce the clinical manifestations in MS. Results: The mechanisms underpinning neurological deficits are described in the relapsing and in the progressive phases, stressing inflammatory and neurodegenerative components, especially demyelination, axonal damage and conduction impairment. Transient worsening based in Uhthoff's phenomenon, mechanisms producing positive symptoms, as paraesthesias and Lhermitte sign due to axonal hiperexcitability and ephaptic interactions, and development of cortical symptoms will also be addressed. The variety of processes leading to neural repair and functional recovery in the remitting phase is focused, as remyelination and adaptive changes due to neural plasticity. Conclusion: The awareness of mechanisms producing symptoms in MS emphasises the role of symptomatic and rehabilitation therapies in the improvement of patients' well-being.
\end{abstract}

Key words: multiple sclerosis, /physiopathology, demyelination, axonal damage.

\section{RESUMO}

A fisiopatologia dos sintomas e sinais na esclerose múltipla (EM) é um tópico pouco divulgado apesar da sua importância na abordagem dos doentes. Objetivo: Foi apresentar os principais mecanismos biofísicos e bioquímicos que produzem manifestações clínicas da EM. Resultados: Descrevem-se os mecanismos subjacentes aos défices neurológicos nas fases de surto e progressivas, realçando as componentes inflamatória e neurodegenerativa, especialmente desmielinização, lesão axonal e alterações da condução. Serão igualmente referidos os sintomas transitórios explicados pelo fenômeno de Uhthoff, a produção de sintomas positivos, como as parestesias e o sinal de Lhermitte por hiperexcitabilidade axonal e interações efáticas, e o desenvolvimento de sintomas corticais. Apresentam-se os diversos processos de reparação neural e de recuperação funcional nas fases de remissão, como a remielinização e as alterações adaptativas por neuroplasticidade. Conclusão: 0 conhecimento dos mecanismos que produzem os sintomas da EM realça o papel das terapêuticas sintomáticas e de reabilitação na melhoria do bem-estar dos doentes.

Palavras-Chave: esclerose múltipla, /fisiopatologia, desmielinização, lesão axonal.

Maybe in accordance with its name, multiple sclerosis (MS), as well as the field of primary demyelinating diseases of the central nervous system (CNS) as a whole, generates daily an impressive number of publications, dedicated to a variety of multiple aspects, turning impossible one to keep up with the immense body of new data. As expected, most studies address issues that are still unknown or need to be better understood, as the aetiology and pathogenesis of MS. In the last two decades, the literature has been flooded with reports of new therapies that allegedly modify the natural history of MS, as such denominated disease-modifying drugs (DMD). It is undeniable that the discovery of DMD represents a remarkable step forward in the control of the disease, is a non-stop research field and brings hope to the possibility of cure. Even so, the positive effects of first-line DMD are considered to be rather modest, since the drugs act in the inflammatory, but not in the neurodegenerative mechanisms of the disease, hence the impact in the long term disability is small, whereas the better efficacy of second-line drugs must be weighed against a poorer safety profile ${ }^{1}$.

Therefore, in the clinical setting, the people afflicted with MS must be subjected to a comprehensive and individualized therapeutically intervention, able to control the symptoms and signs of the disease, thus ameliorating their well-being.

MD, PhD Senior Neurologist and Head of MS Clinic, Department of Neurology, Centro Hospitalar São João. Associate and Aggregate Professor, Faculty of Health Sciences, Universidade Fernando Pessoa, Porto, Portugal.

Correspondence: Maria José Sá; Department of Neurology, Centro Hospitalar São João; Alameda Professor Hernâni Monteiro 4200/319; Porto - Portugal; E-mail:mjsa@med.up.pt

Conflict of interest: There is no conflict of interest to declare.

Received 23 March 2012; Received in final form 16 April 2012; Accepted 23 April 2012 
It must be remembered that MS is a chronic and not curable neurological disease that usually begins in young adults, being the leading cause of non-traumatic neurological disability in early ages, and is unpredictable regarding the clinical manifestations, course and disability. For these reasons, MS represents a major burden to the patients, families, society and health economy ${ }^{2}$.

In effect, the experience of following many patients in our MS Clinic along more than 25 years emphasises the importance of the symptomatic therapy and the rehabilitation approaches, among the global therapeutic armamentarium employed in the disease. As a result and to better understand the role of symptomatic therapies, either pharmacological or non-pharmacological, the physiopathological changes taking place in the demyelinating lesions which compromise the functioning of the nerve fibres, along the disease evolution, must be identified. This topic is not very frequently addressed in the literature targeting neurological clinicians, which may be explained by its complexity and the assumption that those mechanisms belong to biophysical and biochemical disciplines. Despite this supposition, it is certainly pertinent to remember what is going on the CNS when a MS patient becomes paretic, as example of a negative sign, or feels paraesthesias, traducing a positive symptom. Briefly, it has been known since long that the neurological impairment in the early stages is due to the conduction block in demyelinated fibres ${ }^{3}$ whereas irreversible disability is ascribed to axonal transection and neuronal loss ${ }^{4}$. On the other hand, the natural reactive mechanisms that seek to counteract the pathological process thorough myelin repair, in order to normalize the neural functions, are seen in early phases ${ }^{5,6}$, but are progressively lost later ${ }^{7,8}$.

The aim of this work was to revisit the basic mechanisms that underpin the clinical expression of symptoms and signs in multiple sclerosis, which hypothetically may be targeted by symptomatic therapies, in a practical summarized way that can be easily accessed by health professionals dedicated to MS, who wish to understand their patient's symptoms day by day, to better manage the disease. The mechanisms that produce the clinical manifestations in MS will be presented in the next sections according to their type - negative/positive - and the phase of the disease - relapse, remission, progressive — bearing in mind that all processes lead ultimately to axonal injury.

\section{MYELIN AND AXONAL CONDUCTION}

The CNS myelin sheath is a lipid-rich multilayered structure composed of oligodendrocytic plasma membranes wrapping around the CNS axons, which provides insulation for electrical impulses (reviewed in the study of Aggarwal et al. ${ }^{9}$ ). Myelin is a highly stable membrane periodically interrupted by the nodes of Ranvier that are rich in voltage-gated sodium channels.
In myelinated fibres, the action potential jumps rapidly in a saltatory way, from one node to another, promoting the fast processing of information. Briefly, the biophysical properties underlying these phenomena are as follows: the current is generated by the opening of sodium channels in the nodes of Ranvier with a resultant sodium influx and depolarization of the axonal membrane; then, the current moves towards next node and is prevented from flowing out by the myelin sheath in the internodal segments; the electrical flow ends due to the opening of the potassium channels and subsequent repolarization ${ }^{10}$.

In normal conditions, myelinated axons have a safety factor for transmission, defined as the current available to depolarize the axolemma divided by the current necessary to do $\mathrm{so}^{11}$, which is several times higher than threshold. This means that the potential action generated in a node is several times superior to the current necessary to fire the next node.

When myelin is damaged, the safety factor is reduced to around the unit and the conduction of demyelinated axons is successful or unsuccessful depending on the milieu conditions ${ }^{12-15}$. As a result, the axon suffers consequent physiological changes, such as loss of saltatory properties of electrical conduction, reduction in conduction velocity and a predisposition to conduction block.

\section{Mechanisms of symptoms production in the relapsing phase}

During relapses, MS patients lose partial or totally some type of physiological functions, traduced by a variety of negative symptoms, as, for instance, paresis, hyposthesia, visual impairment, diplopia or ataxia. As daily testified in MS Clinics, the variability in the clinical manifestations is high among patients, as well as in different phases of the disease in each patient. The symptomatic expression depends not only on the location of MS lesions but also on the variety of conduction properties displayed by affected axons.

The main cause of relapse is the failure of axonal conduction at the site of a lesion, which is due to axonal changes, related both to acute inflammation and demyelination, which possibly act in sequential phases and ultimately proceed together in a complex way. As well, there is evidence that axons may be directly injured and that glial dysfunction may also play a role.

The impairment in the axonal transmission may be mainly functional due to inflammation, oedema and toxic action of products released in the MS plaques, which happens in the earlier acute phases of a relapse, or entirely structural, in later phases, when axon is exposed by myelin damage in internodal segments and also by direct axonal injury in the nodal and perinodal regions (Table 1).

\section{Inflammation}

Inflammation may be sufficient to provoke significant clinical deficits without demyelination. 
The recognition that inflammatory components are able to disclose clinical symptoms derives from the knowledge that the very first event in the new lesions located in clinically eloquent areas, related to relapses, is the appearance of inflammatory markers after the focal breakdown of the blood-brain-barrier (BBB) $)^{16}$. Some substances released upon the formation of a new lesion have been pointed out to mediate the biophysical consequences of inflammation, leading to transient impairment or block of nerve conduction, such as cytokines, nitric oxid (NO) and antibodies against ion channels. Moreover, proinflammatory cytokines - tumor necrosis factor (TNF)-alpha and interferon gama - may stimulate the formation of inducible form of the enzyme nitric oxide syntetase with further liberation of NO, that is a mediator of axonal block, particularly in axons affected by demyelination ${ }^{17}$.

The inflammatory mediators are thought to block axonal conduction by a variety of mechanisms that affect ion channels, particularly sodium channels, and mitochondrial energy production ${ }^{12}$. Besides, the BBB breakdown also may induce changes in the electrophysiology of axons due to leakage of fluid and substances that alter the composition of the extracellular spaces that bathe nervous fibres ${ }^{18}$.

Whether the inflammatory response may lead to neurological symptoms by itself or needs the coexistence of demyelination is still matter of debate.

\section{Demyelination}

The myelin damage in MS is characteristically segmental, resulting in the loss of whole internode of myelin, and occurs in the typical lesions of the white matter, as well as in cortical lesions. In segmental demyelination, conduction specifically fails at the site of the lesion, whereas the unaffected parts of the axon on either side of the lesion continue to conduct normally ${ }^{19}$.

Since the damage of myelin, sheath eliminates the insulator of the internodal segments, the axonal current flow is locally interrupted and short-circuited through the uncovered portions of the axon; however, as the density of sodium channels in the axolemma beneath the internodal myelin sheath is low, the impulse propagation is inhibited, leading to a much slower current flow or to its interruption ${ }^{20}$. Further propagation of the action potential is blocked due to the exposition of voltage-gated potassium channels normally restricted to the internodes. An abnormal redistribution of sodium channels on demyelinated axons has been reported, both in experimental models ${ }^{21}$ and in MS lesions ${ }^{21,22}$, with loss of nodal aggregates and appearance of a diffuse expression along the denuded portions of the axon.

Given the high safety factor for transmission, demyelination is usually not critical in small portions of the axons ( 1 or 2 internodes), whereas in longer segments the current tends

Table 1. Mechanisms that impair axonal conduction and produce clinical manifestations in multiple sclerosis.

\begin{tabular}{|c|c|c|c|}
\hline Symptoms & Relapse & $\begin{array}{c}\text { Transient } \\
\text { worsening }\end{array}$ & Persistent deficits \\
\hline $\begin{array}{l}\text { Negative } \\
\text { Impairment of } \\
\text { functional systems } \\
\text { (motor, sensory, } \\
\text { visual, etc.) }\end{array}$ & $\begin{array}{l}\text { Inflammation: BBB breakdown, inflammatory } \\
\text { mediators (cytokines, NO) and altered composition } \\
\text { of extracellular fluid. } \\
\text { Demyelination: segmental interruption of axonal } \\
\text { conduction, short-circuited current, slower } \\
\text { continuous propagation in denuded internodes } \\
\text { and abnormal exposure of ionic channels. } \\
\text { Axonal damage: functional (oedema) and structural } \\
\text { (internodal, nodal and perinodal) injury and } \\
\text { redistribution of nodal sodium channels. } \\
\text { Dysfunction of glial cells: astrocytes (BBB } \\
\text { breakdown, impairment of ionic channel) and } \\
\text { oligodendrocytes (disturbance of myelin sheaths). }\end{array}$ & $\begin{array}{l}\text { Uhthoff's } \\
\text { phenomenon: } \\
\text { changes in the } \\
\text { electrical properties } \\
\text { of demyelinated } \\
\text { axons upon raised } \\
\text { body temperature. }\end{array}$ & $\begin{array}{l}\text { Axonal transection: immunological and } \\
\text { inflammatory mediators, exposure to } \\
\text { NO (mitochondrial dysfunction, energy } \\
\text { failure, altered ionic channels, influx } \\
\text { of calcium into the axoplasma), lack of } \\
\text { trophic support by oligodendrocytes, } \\
\text { exposure to sustained impulse activity. } \\
\text { Persistent conduction block } \\
\text { Wallerian degeneration } \\
\text { Axonal and neuronal loss } \\
\text { Synaptic damage }\end{array}$ \\
\hline $\begin{array}{l}\text { Positive } \\
\text { Paraesthesias, } \\
\text { trigeminal neuralgia, } \\
\text { tonic spasms } \\
\text { and Lhermitte's }\end{array}$ & $\begin{array}{l}\text { Hyperexcitability phenomena in the exposed } \\
\text { axolemma: spontaneous ectopic impulses, } \\
\text { synchronous axonal discharges, "reflected" } \\
\text { impulses, ephaptic interactions and acquisition of } \\
\text { mechanosensitivity. }\end{array}$ & & \\
\hline $\begin{array}{l}\text { Cortical } \\
\text { Cognitive dysfunction }\end{array}$ & $\begin{array}{l}\text { Inflammation: disturbance of synaptic } \\
\text { transmission due to inflammatory mediators } \\
\text { (cytokines, NO), changes in the composition of } \\
\text { extracellular fluid and glutamate. } \\
\text { Neurodegeneration: glial and neuronal and } \\
\text { synaptic loss. }\end{array}$ & & \\
\hline
\end{tabular}

BBB: blood-brain-barrier; NO: nitric oxide. 
to flow by continuous propagation. Conduction failure may also be caused by partial myelin thinning along the internode and may be even more striking upon myelin loss in the paranodal region ${ }^{14}$.

\section{Axonal damage}

The occurrence of axonal damage in MS is an old observation described by Charcot $^{23}$, which has been revisited and firmly supported in the last years ${ }^{4}$. The spectrum of axonal damage may vary from a functional and temporary effect as a result of oedema during relapses to fibre transaction provoking persistent neurological sequels.

Marked axonal damage may be found in early disease stages and acute axonal injury correlates with inflammatory cells. During a new relapse, the direct harmful stimuli to the axons include axon-specific antibodies plus complement, CD8 T+ cells perforin, myelin-specific CD4 T+ cells, NO, matrix metalloproteinases and glutamate ${ }^{24,25}$. Besides suffering the effects of myelin damage in demyelinated portions, axons may be also directly injured in the nodal and perinodal regions, the latter including the paranodes and the juxtaparanodes ${ }^{26}$. These nodal and perinodal domains may be impaired by effects of inflammation and axonal swelling, leading to direct and early axonal loss, even in the absence of demyelination. Nodal widening is sufficient to block conduction. Some authors suggest that the axoglial junction in the paranodes, which comprise the axonal adhesion proteins Caspr and contactin, is an area of particular vulnerability during the initial stages of tissue damage and emphasise the possibility of axoglial antigens being targets for autoimmunity in $\mathrm{MS}^{27}$ and acting like inductors of demyelination. In addition, there is a higher axonal vulnerability due to damaged myelin and demyelination, because when the axon is devoid of myelin there is a redistribution of the nodal sodium channels that might manipulate the functions and survival of axons.

The mechanisms of axonal transection and permanent loss that provoke persistent neurological deficits will be later described in this article.

\section{Dysfunction of glial cells}

In addition, there is evidence that dysfunction of glial cells might influence the conduction properties of axons. Hence, astrocytic changes not only disturb the integrity of the BBB but also may impair the organization of the ionic channels along the axonal membrane, and oligodendrocytic injury disturbs the trophic role to the myelin sheaths, further harming the axoglial junctions in paranodes ${ }^{14}$.

\section{Mechanisms of transient symptomatic worsening}

Apart from relapses, most people with MS experience transient worsening of usual clinical signs and symptoms, which affect daily life activities, and their complains are sometimes difficult to distinguish from relapses, unless patients are seen by an experienced neurologist. The daily routine practice in a MS Clinic teaches us that even mildly disabled MS patients may report temporary difficulties in usual motor tasks, as for instance walking or housekeeping, yet sometimes are not able to describe very well the duration of those episodes.

This temporary worsening of function is known since Wilhelm Uhthoff's descriptions that symptoms can aggravate upon heating and improve with body cooling ${ }^{28}$; namely, after a hot bath or strong exercise, MS patients with a history of optic neuritis reported reversible and stereotyped alterations in vision ${ }^{29}$. Since then, the heat sensitivity in MS is unanimously recognized and the transient worsening of neurological signs and symptoms consequent to raised body temperature in MS patients is denominated Uhthoff's phenomenon $^{29}$. This phenomenon led to define the diagnostic "hot bath test" for patients suspected to have $\mathrm{MS}^{30}$.

Clinically, the impairment explained by Uhthoff's phenomenon is felt in physical and/or neuropsychological functions and may occur after passive heat exposure (high ambient temperatures) and/or after patient's exercise; stressful situations leading to increased body temperature may also account for some cases ${ }^{31}$. Transient neurological worsening has also been described in relation to temperature variations due to circadian rhythms as the menstrual cycles ${ }^{32}$. In a general way, clinical manifestations of MS, including fatigue, worsen with heating and ameliorate with cooling, which is explained by the restoration of conduction in demyelinated axons and decrease in nitric oxide (NO) production induced by decrease in the temperature ${ }^{14}$. That is why, in the clinical setting, MS patients are usually advised to avoid situations that might increase the body temperature.

The physiopathological basis for the Uhthoff's phenomenon has also been attributed to demyelination and consequent reduction in axonal cross-sectional area, thereby decreasing the conduction velocity, and to loss of internodal conduction, with a predisposition to conduction slowing and block (Table 1). The warming might change the electrical properties of the demyelinated axon and block of conduction ensues thorough an increase in the rate of recovery processes (potassium channel activation and sodium channel inactivation), which surpass the action potential, generating processes (sodium channel activation) ${ }^{31}$.

\section{Mechanisms of positive symptoms}

Contrariwise to the above-mentioned negative neurological symptoms, some MS patients have spontaneous abnormal motor and, most frequently, sensory feelings, which are known as positive symptoms: paraesthesias/disesthesias, neuropathic pain, trigeminal neuralgia, triggered sensations, paroxysmal manifestations (tonic muscle spasms, paroxysmal itching, facial myokimia, episodic dysarthria) and movement induced sensations (visual phosphenes, Lhermitte's phenomenon). 
The mechanisms underlying these curious and sometimes disabling symptoms are based in hyperexcitability phenomena arising in the exposed axolemma in response to demyelination, that can be induced by mechanical stimulation, and somehow vary according to the type of symptomatology (Table 1). Briefly, the demyelinated axolemma may generate spontaneous ectopic impulses, the axons may depolarise together in synchronous discharges and ephaptic interactions may occur between adjacent fibres ${ }^{12}$. Ephapse is defined as a point of lateral contact (other than a synapse) between nerve fibres across which impulses are conducted directly through the nerve membranes.

Regarding paraesthesias, there is evidence that some days after demyelination the axons may acquire the property of generating spontaneous activity in the form of trains of spurious impulses, that may last hours in the absence of stimulus and assume two patterns, either regularly spaced impulses at frequencies of 10-50 Hz related to slow influx of sodium current in demyelinated regions, or bursts of impulses explained by inward potassium current ${ }^{12}$. Tingling sensations may be explained by ectopic activity, and ephaptic transmission between physically adjacent fibres and triggered sensations may as well result from prolonged bursts of ectopic impulses provoked by the passage of normal impulses in demyelinated axon and the production of "reflected" impulses that travel in the opposite direction from sites of demyelination ${ }^{12}$. The report of symptoms evoked by body movements that induce a physical distortion of nerve fibres suggests that demyelinated axons may become mechanosensitive. Among movement induced sensations, perhaps the most widely known positive manifestation in MS is the abnormal and disagreeable electric schock-like sensation that some patients feel in the midline trunk upon neck flexion, sometimes irradiating to the limbs, known as Lhermitte's phenomenon ${ }^{33}$ that has been related to MS plaques located in the dorsal columns of cervical cord. Movement induced sensations are attributed to the possibility of demyelinated axolemma acquiring ion channel characteristics resembling those of mechanoreceptors and being able to generate ectopic discharges in response to mechanical distortion ${ }^{34}$.

\section{Mechanisms of cortical symptoms}

MS has been traditionally considered a white matter disease, yet there is a large body of evidence from histopathological and magnetic resonance imaging (MRI) findings that demyelinating lesions may also involve the grey matter structures, mainly the cerebral cortex, but also deep grey nuclei ${ }^{35}$. However, symptoms thoroughly ascribed to grey matter lesions are uncommonly reported.

Regarding cortical dysfunction, the most prevailing manifestation is cognitive impairment, reported to occur in 40$60 \%$ MS patients ${ }^{36}$, whereas aphasia, hemianopsia or epilepsy, are not frequently observed. Cortical demyelination has been found in $90 \%$ of MS autopsy cases, can be detected in early MS and predominates in late progressive forms. Cortical lesions are common in chronic MS and may extend over several gyri; regarding location, they can be contiguous with the subcortical white matter (type I, leukocortical), restricted to the cortex (type II, intracortical) or extend from the pial surface to cortical layers III-IV (type III, subpial) ${ }^{37}$. The diagnosis of cortical lesions requires special MRI techniques and is indirectly given by measuring the degree of cortical atrophy, which is a major correlate of disability and cognitive impairment ${ }^{38}$.

The mechanisms that lead to grey matter pathology are unclear, yet it is plausible that inflammatory and demyelinating changes are both implied (Table 1). Cortical lesions show more neurodegenerative changes, namely glial, neuronal and synaptic loss ${ }^{39}$ than inflammatory findings. Several factors associated with inflammation can also disturb synaptic transmission, including cytokines - interleukin 1, interleukin 2, TNF alpha - and especially NO. In addition, changes in the composition of extracellular fluid due to BBB disruption may also affect synaptic function, as well as glutamate and other neurotransmitters liberated by activated microglia and leukocytes ${ }^{40}$.

\section{Mechanisms of neurological recovery in the remitting phase}

In most MS patients, the disease evolves, at least in the earlier phases, with remitting periods. The clinical recovery may be total or partial and remissions are expected to be longer in patients treated with $\mathrm{DMD}^{1}$. Various mechanisms underpin the recovery of functions, acting in different aspects and levels of myelin and axonal impairment (Table 2); however, the CNS repair has a dual face, so that some patients experience neurological symptoms related to defects in axonal conduction. Most authors believe that restorative factors vary from patient to patient and also at different times in the same patients.

For the sake of simplicity, the mechanisms of repair that explain the re-establishment of axonal conduction, clinically traduced by remission, can be basically grouped in four categories: resolution of inflammation, remyelination, acquisition of internodal excitability in demyelinated axons and adaptive changes. The first two processes occur typically in earlier phases, whereas more delayed recovery may reflect the use of alternative neuronal pathways or an increase of internodal sodium channels. In addition, there is also the possibility of partial recovery in later progressive phases of MS, the mechanisms of which will be described in the next section.

\section{Resolution of inflammation}

After the inflammatory reaction occurring in the relapse, the natural mechanisms of repair set the stage to restore the normal conditions around the nerve fibres with impaired 
conduction and myelin damage. Therefore, the earlier events are the resolution of oedema, reduction of cell infiltrates around the vessels and dissolution of cytokines, with the consequent relief of functional deficits.

\section{Remyelination}

Regarding the restoration of conduction by remyelination, the naturally expected reaction after CNS myelin damage, there is evidence that oligodendrocyte progenitor cells migrate to the lesions and differentiate into premyelinating oligodendrocytes that extend processes to demyelinated axons ${ }^{7}$. This phenomenon may be active in the early phase of the disease $\mathrm{e}^{41}$, where remyelination is extensive; however, as the disease progresses, remyelination is incomplete in chronic white matter lesions and ineffective in most cases ${ }^{42}$. Remyelination was found to occur in about $40 \%$ of all MS plaques $^{43}$, traduced by the formation of uniformly thin myelin sheaths and shadow plaques. In addition, there is evidence that remyelination is more extensive in the cortex than in white matter lesions ${ }^{44}$ and is still present, but limited, in most chronic MS white matter lesions. Apart from remyelination, it must be emphasised that demyelinated axons placed in ideal conditions might be able to conduct the nervous impulse, namely when axonal diameter is small and the internode preceding the damaged segment is short, as happens in the axons of the optic nerves and pyramidal tracts, explaining the possibility of recovery from lesions in those pathways ${ }^{14}$.

\section{Internodal excitability}

Demyelinated axons are also able to acquire internodal excitability in the absence of remyelination, due to the appearance of sodium channels along demyelinated axolemma and consequent possibility of a continuous or microsaltatory way of conduction ${ }^{45,46}$. Notwithstanding, this apparent restoration leads to several defects in the characteristics of conduction, which becomes slower and with increased refractory periods, that may be clinically traduced by neurological symptoms ${ }^{13}$. The slower conduction explains the characteristic delay in the latency of evoked potentials, which has a diagnostic role; the increase in the refractory period difficult the conduction of impulse pairs at physiological frequencies, thus leading to impaired sensation and muscle weakness. In demyelinated axons, the refractoriness accumulates with repeated activation, so the maximum transmissible frequency becomes progressively poorer during sustained activity; besides, after conduction of impulse trains, intermittent conduction block may ensue because of axolemma hyperpolarization (excessive activity of the sodium pump in response to increased intra-axonal sodium concentration in prior impulse activity); all these situations might explain, for instance, the progressive weakness after walking short distances ${ }^{47}$.

\section{Adaptive changes}

Neural plasticity, an outstanding attribute of the nervous system which enables its adaptation to physiological and pathological changes, gives an important contribution to the restoration of functional loss in many neurological diseases. The spectrum of neuroplastic modifications is wide, ranging from large-scale changes in brain areas after an injury to the molecular level underpinning learning, and may be structural (axonal sprouting, dendritic spine changes, formation of new synapses) or functional (brain areas adjacent to the damaged region assume the lost function).

Briefly, the adaptive changes of the CNS after injuries are better known since the introduction of functional MRI studies and transcranial magnetic stimulation, and may have a rapid-onset through the activation of other anatomic regions that assume the function of damaged areas, and a long-term duration, relying in the establishment of new neuronal connections. In MS patients, functional brain reorganization mainly consists of an increase in the extent of activation of the brain areas used by healthy subjects, as well as the recruitment of additional brain areas ${ }^{48}$. Neural plasticity is a recent and promising research field in MS, addressed in the literature with studies showing adaptive compensation for motor $^{49,50}$, visual ${ }^{51}$, memory and other cognitive tasks ${ }^{52-54}$, even in the resting state ${ }^{55}$ and in benign forms ${ }^{56,57}$.

Table 2. Mechanisms of neural repair and clinical recovery in multiple sclerosis.

\begin{tabular}{ll}
\multicolumn{1}{c}{ Remitting phases } & \multicolumn{1}{c}{ Progressive phases } \\
\hline Resolution of inflammation: resolution of oedema, reduction of perivascular cell \\
infiltrates and dissolution of cytokines. \\
Remyelination: migration of oligodendrocyte progenitor cells to demyelinating \\
lesions and formation of thin myelin sheaths by premyelinating
\end{tabular}




\section{Mechanisms of persistent neurological deficits}

Permanent neurological deficits in MS originate after a gradual accumulation of persistent manifestations, particularly in later progressive phases, when repair mechanism loose efficacy and are no longer able to restore functions; thereby, the neurodegenerative character of the disease surpasses the inflammatory component. Histopathological studies indicate that chronic MS lesions display demyelination, axonal loss, fibrillary gliosis ad less inflammation than acute lesions ${ }^{14}$.

Several mechanisms contribute to the irreversible permanent neurological disability experienced by MS patients, as loss of axons, dendrites and neurons, persistent block conduction and synaptic damage (Table 1). Actually, in parallel to the axonal damage occurring in acute, inflammatory demyelinating lesions in a proportional magnitude to the intensity of inflammation, axons suffer a slow degenerative process in chronic inactive MS plaques ${ }^{14}$. As expected, irreversible axonal and neuronal loss is the most fearful pathological situation occurring in MS patients since it is correlated with disability.

The mechanisms of progressive axonal damage and transection in chronic phases are various and not completely understood, involving immunological factors and exposure to inflammatory mediators as previously described, as well as lack of trophic support by oligodendroglia resulting from a disturbed axon-glia interaction, and exposure to sustained impulse activity ${ }^{13}$. In fact, axonal degeneration seems to depend of impulse activity, especially when previously demyelinated portions are exposed to NO, which is liberated in high amounts in MS lesions. In this situation, the conduction block becomes permanent. It is assumed that axons subjected to sustained impulse activity have increased metabolic needs, however their metabolic capacity is low due to mitochondrial inhibition by NO, as well as altered ionic homeostasis leading to calcium accumulation ${ }^{13}$. In its turn, mitochondrial dysfunction and energy failure impair the exchanges between sodium and calcium, with entrance of calcium into the axoplasma, inducing persistent axonal damage. Upon transection there is Wallerian degeneration and deafferentiation. Persistent conduction block may also appear in some axons despite the possibility of acquiring internodal excitability mentioned above, mechanism that may not occur in all demyelinated axons. Some factors contribute to abnormal conduction in those axons, as the inability to conduct at usual body temperature consequent to biophysical changes and altered composition of the extracellular fluid ${ }^{13}$. It deserves to be mentioned that Wallerian degeneration has been also evidenced in normal appearing white matter in acute $\mathrm{MS}^{58}$.

\section{Mechanisms of possible partial recovery in progressive phases}

When MS patients enter later stages with progressive course, especially if the disease was not preceded by relapses and remissions, the hope of neurological recovery is usually minute. However, in the clinical practice, some patients are seen to have periods of stability or even symptomatic amelioration in those stages, which has been attributed to compensatory and adaptive CNS changes, since remyelination is limited in chronic phases.

Recent research applying functional MRI techniques evidenced that brain plasticity for visuomotor practice is preserved even in MS patients with high lesion burden, due to activation of cognitive systems different from those seen in controls, addressing the possibility of persistent adaptive plasticity and repair ${ }^{59}$. Moreover, there is evidence that cortical reorganization of motor functions takes place until late in the course of the disease, with activating mechanisms that vary in different stag$\mathrm{es}^{60}$. Therefore, the role of comprehensive rehabilitation strategies that might assist neural plasticity in chronically disabled patients must be emphasised.

\section{References}

1. Mendes A, Sá MJ. Classical immunomodulatory therapy in multiple sclerosis: how it acts, how it works. Arq Neuropsiquiatr 2011;69:536-543.

2. Costa D, Sá MJ, Calheiros JM. The effect of social support on the quality of life of patients with multiple sclerosis. Arq Neuropsiquiatr 2012;70:108-113.

3. McDonald WI, Sears TA. Effect of demyelination on conduction in the central nervous system. Nature 1969;221:182-183.

4. Trapp BD, Peterson J, Ransohoff RM, Rudick R, Mörk S, Bö L. Axonal transection in the lesions of multiple sclerosis. N Engl J Med 1998;338:278-285.

5. Smith EJ, Blakemore WF, McDonald WI. Central remyelination restores secure conduction. Nature 1979;280:395-396.

6. Prineas JW, Connell F. Remyelination in multiple sclerosis. Ann Neurol 1979;5:22-31.

7. Chang A, Tourtellotte WW, Rudick R, Trapp BD. Premyelinating oligodendrocytes in chronic lesions of multiple sclerosis. N Engl J Med 2002;346:165-173.

8. Noseworthy JH, Lucchinetti C, Rodriguez M, Weinshenker BG. Multiple sclerosis. N Engl J Med 2000;343:938-952.
9. Aggarwal S, Yurlova L, Simons M. Central nervous system myelin: structure, synthesis and assembly. Trends Cell Biol 2001;21:585-593.

10. Lublin FD, Miller AE. Multiple sclerosis and other inflammatory demyelinating diseases of the central nervous system. In: Bradley WG, Daroff RB, Fenichel GM, Jankovic J (Eds). Neurology in Clinical Practice. 5th edition. Philadelphia: Elsevier; 2008:1584-1585.

11. Rushton WAH. Initiation of the propagated disturbance. Proc Roy Soc Lond B Biol Sci 1937;124:210-243.

12. Smith JK, McDonald WI. The pathophysiology of multiple sclerosis: the mechanisms underlying the production of symptoms and the natural history of the disease. Philos Trans R Soc Lond B Biol Sci 1999;354:1649-1673.

13. Smith KJ, McDonald WI. Mechanisms of symptoms production. In: McDonald WI, Noseworthy JH (Eds). Multiple Sclerosis 2. Philadelphia: Elsevier; 2003:59-74.

14. Smith K, McDonald I, Miller D, Lassmann H. The pathophysiology of multiple sclerosis. In: Compston A, Confavreux C, Lassmann H, et al. (Eds). McAlpine's Multiple Sclerosis. 4th edition. Philadelphia: Elsevier; 2006:601-659. 
15. Peterson JW, Trapp BD. Neuropathology of multiple sclerosis. Neurol Clin 2005;23:107-129.

16. Cotton F, Weiner HL, Jolesz FA, Guttmann CR. MRI contrast uptake in new lesions in relapsing-remitting MS followed at weekly intervals. Neurology 2003;60:640-646.

17. Hu S, Sheng WS, Peterson PK, Chao CC. Differential regulation by cytokines of human astrocyte nitric oxide production. Glia 1995;15:491-494.

18. Abbott NJ. Inflammatory mediators and modulation of blood-brainbarrier permeability. Cell Mol Neurobiol 2000;20:131-147.

19. McDonald WI. The effects of experimental demyelination on conduction in peripheral nerve: a histological and electrophysiological study. II. Electrophysiological observations. Brain 1963;83:501-524.

20. Utzschneider DA, Thio C, Sontheimer H, Ritchie JM, Waxman SG, Kocsis JD. Action potential conduction and sodium channel content in the optic nerve of myelin-deficient rat. Proc Biol Sci 1993;254:245-250.

21. Craner MJ, Newcombe J, Black JA, Hartle C, Cuzner ML, Waxman SG. Molecular changes in neurons in multiple sclerosis: altered axonal expression of Nav1.2 and Nav1.6 sodium channels and $\mathrm{Na}+/ \mathrm{Ca} 2+$ exchanger. Proc Natl Acad Sci USA 2004;101:8168-8173.

22. Coman I, Aigrot MS, Seilhean D, et al. Nodal, paranodal and juxtaparanodal axonal proteins during demyelination and remyelination in multiple sclerosis. Brain 2006;129:3186-3195.

23. Charcot M. Histologie de la sclerose en plaques. Gaz Hosp 1868;141:554-578.

24. Neumann H, Medana IM, Bauer J, Lassmann H. Cytotoxic T lymphocytes in autoimmune and degenerative CNS diseases. Trends Neurosci 2002;25:313-319.

25. Mathey EK, Derfuss T, Storch MK, et al. Neurofascin as a novel target for autoantibody-mediated axonal injury.J Exp Med 2007;204:2363-2372.

26. Desmazières A, Sol-Foulon N, Lubetzki C. Changes at the nodal and perinodal axonal domains: a basis for multiple sclerosis pathology? Mult Scler J 2012;18:133-137.

27. Derfuss T, Linington C, Hohlfeld R, Meinl E. Axo-glial antigens as targets in multiple sclerosis: implications for axonal and grey matter injury.J Mol Med 2010;88:753-761.

28. Uhthoff W. Untersuchungen uber bei del multiplen Herdsklerose vorkommenden Augenstorungen. Arch Psychiatr Nervenkrankh 1890;21:55-116.

29. Selhorst JB, Saul RF. Uhthoff and his symptom. J Neuroophthalmol 1995;15:63-69.

30. Malhotra AS, Goren $\mathrm{H}$. The hot bath test in the diagnosis of multiple sclerosis. JAMA 1981;246:1113-1114.

31. Frohman TC, Davis SL, Frohman EM. Modeling the mechanisms of Uhthoff's phenomenon in MS patients with internuclear ophthalmoparesis. Ann N Y Acad Sci 2011;233:313-319.

32. Namerow NS. Circadian temperature rhythm and vision in multiple sclerosis. Neurology 1968;18:417-422.

33. Lhermitte J, Bollack J, Nicholas M. Les douleurs à type de décharge électrique consécutives à flexion céphalique dans la sclérose en plaques. Rev Neurol 1924;2:56-62.

34. Nordin M, Nystron B, Wallin U, Hagbarth KE. Ectopic sensory discharges and paresthesiae in patients with disorders of peripheral nerves, dorsal roots and dorsal columns. Pain 1984;20:231-245.

35. Vercellino M, Masera S, Lorenzatti M, et al. Demyelination, inflammation, and neurodegeneration in multiple sclerosis deep gray matter. J Neuropathol Exp Neurol 2009;68:489-502.

36. Rao SM, Leo GJ, Bernardin L, Unverzagt F. Cognitive dysfunction in multiple sclerosis. 1. Frequency, patterns, and prediction. Neurology 1991;41:685-691.

37. Peterson JW, Bö L, Mörk S, Chang A, Trapp BD. Transected neurites, apoptotic neurons, and reduced inflammation in cortical multiple sclerosis lesions. Ann Neurol 2001;50:389-400.

38. Fisher E, Lee JC, Nakamura K, Rudick RA. Gray matter atrophy in multiple sclerosis: a longitudinal study. Ann Neurol 2008;64:255-265.
39. Wegner C, Esiri MM, Chance SA, Palace J, Matthews PM. Neocortical neuronal, synaptic, and glial loss in multiple sclerosis. Neurology 2006;67:960-967.

40. Piani D, Frey K, Do KQ, Cuénod M, Fontana A. Murine brain macrophages induce NMDA receptor mediated neurotoxicity in vitro by secreting glutamate. Neurosci Lett 1991;133:159-162.

41. Patrikios P, Stadelmann C, Kutzelnigg A, et al. Remyelination is extensive in a subset of multiple sclerosis patients. Brain 2006;129:3165-3172.

42. Goldschmidt T, Antel J, König FB, Brück W, Kuhlmann T. Remyelination capacity of the MS brain decreases with disease chronicity. Neurology 2009;72:1914-1921.

43. Barkhof F, Bruck W, De Groot CJ, et al. Remyelinated lesions in multiple sclerosis: magnetic resonance image appearance. Arch Neurol 2003;60:1073-1081.

44. Albert M, Antel J, BrückW, Stadelmann C. Extensive cortical remyelination in patients with chronic multiple sclerosis. Brain Pathol 2007;17:129-138.

45. Felts PA, Deerink TJ, Ellisman $\mathrm{MH}$, et al. Sodium and potassium channel immunolocalisation in demyelinated and remyelinated central axons. Neuropathol Appl Neurobiol 1998;24:154-155.

46. Moll C, Mourre C, Lazdunski M, Ulrich J. Increase of sodium channels in demyelinated lesions of multiple sclerosis. Brain Res 1991;556:311-316.

47. McDonald WI. Mechanisms of functional loss and recovery in spinal cord damage. Outcome of severe damage to the central nervous system. Ciba Found Symp 1975;23-33.

48. Pantano P, Mainero C, Caramia F. Functional brain reorganization in multiple sclerosis: evidence from fMRI studies. J Neuroimaging 2006;16:104-114.

49. Wegner C, Filippi M, Korteweg T, et al. Relating functional changes during hand movement to clinical parameters in patients with multiple sclerosis in a multi-centre fMRI study. Eur J Neurol 2008;15:113-122.

50. Wang J, Hier DB. Motor reorganization in multiple sclerosis. Neurol Res 2007;29:3-8.

51. Werring DJ, Bullmore ET, Toosy AT, et al. Recovery from optic neuritis is associated with a change in the distribution of cerebral response to visual stimulation: a functional magnetic resonance imaging study. J Neurol Neurosurg Psychiatry 2000;68:441-449.

52. Hulst HE, Schoonheim MM, Roosendaal SD, et al. Functional adaptive changes within the hippocampal memory system of patients with multiple sclerosis. Hum Brain Mapp 2011. doi: 10.1002/hbm.21359.

53. Staffen W, Mair A, Zauner H, et al. Cognitive function and fMRI in patients with multiple sclerosis: evidence for compensatory cortical activation during an attention task. Brain 2002;125:1275-1282.

54. Colorado RA, Shukla K, Zhou Y, Wolinsky JS, Narayana PA. Multitask functional MRI in multiple sclerosis patients without clinical disability. Neuroimage 2012;59:573-581.

55. Liu Y, Liang P, Duan Y, et al. Brain plasticity in relapsing-remitting multiple sclerosis: evidence from resting-state fMRI.J Neurol Sci 2011;304:127-131.

56. Giorgio A, Portaccio E, Stromillo ML, et al. Cortical functional reorganization and its relationship with brain structural damage in patients with benign multiple sclerosis. Mult Scler 2010;16:1326-1334.

57. Rocca MA, Ceccarelli A, Rodegher M, et al. Preserved brain adaptive properties in patients with benign multiple sclerosis. Neurology 2010;74:142-149.

58. Bjartmar C, Kinkel RP, Kidd G, Rudick RA, Trapp BD. Axonal loss in normal-appearing white matter in a patient with acute MS. Neurology 2001;57:1248-1252.

59. Tomassini V, Johansen-Berg H, Jbabdi S, et al. Relating brain damage to brain plasticity in patients with multiple sclerosis. Neurorehabil Neural Repair 2012;26:581-593.

60. Rocca MA, Colombo B, Falini A, et al. Cortical adaptation in patients with MS: a cross-sectional functional MRI study of disease phenotypes. Lancet Neurol 2005;4:618-626. 